\title{
Rhabdomyosarcoma: Current Challenges and Their Implications for Developing Therapies
}

\author{
Simone Hettmer, Zhizhong Li, Andrew N. Billin, Frederic G. Barr, D.D.W. Cornelison, \\ Alan R. Ehrlich, Denis C. Guttridge, Andrea Hayes-Jordan, Lee J. Helman, \\ Peter J. Houghton, Javed Khan, David M. Langenau, Corinne M. Linardic, Ranadip Pal, \\ Terence A. Partridge, Grace K. Pavlath, Rossella Rota, Beat W. Schäfer, Janet Shipley, \\ Bruce Stillman, Leonard H. Wexler, Amy J. Wagers' ${ }^{1}$, and Charles Keller ${ }^{1}$ \\ Correspondence: amy_wagers@harvard.edu; charles@cc-TDI.org
}

Rhabdomyosarcoma (RMS) represents a rare, heterogeneous group of mesodermal malignancies with skeletal muscle differentiation. One major subgroup of RMS tumors (so-called "fusion-positive" tumors) carries exclusive chromosomal translocations that join the DNAbinding domain of the PAX3 or PAX7 gene to the transactivation domain of the FOXO1 (previously known as $F K H R$ ) gene. Fusion-negative RMS represents a heterogeneous spectrum of tumors with frequent $R A S$ pathway activation. Overtly metastatic disease at diagnosis is more frequently found in individuals with fusion-positive than in those with fusion-negative tumors. RMS is the most common pediatric soft-tissue sarcoma, and approximately $60 \%$ of all children and adolescents diagnosed with RMS are cured by currently available multimodal therapies. However, a curative outcome is achieved in $<30 \%$ of high-risk individuals with RMS, including all those diagnosed as adults, those diagnosed with fusionpositive tumors during childhood (including metastatic and nonmetastatic tumors), and those diagnosed with metastatic disease during childhood (including fusion-positive and fusion-negative tumors). This white paper outlines current challenges in RMS research and their implications for developing more effective therapies. Urgent clinical problems include local control, systemic disease, need for improved risk stratification, and characterization of differences in disease course in children and adults. Biological challenges include definition of the cellular functions of PAX-FOXO1 fusion proteins, clarification of disease heterogeneity, elucidation of the cellular origins of RMS, delineation of the tumor microenvironment, and identification of means for rational selection and testing of new combination therapies. To streamline future therapeutic developments, it will be critical to improve access to fresh tumor tissue for research purposes, consider alternative trial designs to optimize early clinical testing of candidate drugs, coalesce advocacy efforts to garner public and industry support, and facilitate collaborative efforts between academia and industry.

\footnotetext{
${ }^{1}$ These authors contributed equally to this work.

Copyright (C) 2014 Cold Spring Harbor Laboratory Press; all rights reserved; doi: 10.1101/cshperspect.a025650 Cite this article as Cold Spring Harb Perspect Med 2014;4:a025650
} 
S. Hettmer et al.

$\mathrm{R}^{\mathrm{h}}$ habdomyosarcomas (RMSs) are exceedingly rare and varied mesodermal cancers, linked by their common propensity to undergo aberrant, partial skeletal muscle differentiation (Parham 2001). RMS tumors can occur at any age, but most diagnoses are made in children and adolescents with an annual RMS incidence of 4.3 cases per one million people younger than 20 years of age (Sultan et al. 2009; Perez et al. 2011). There are approximately 350 new diagnoses of childhood RMS in the United States per year. The annual RMS incidence in adults is not entirely clear, but data from the public access Surveillance, Epidemiology and End Results database (Sultan et al. 2009) show that $40 \%$ of all RMS tumors are diagnosed in adults $>20$ years of age.

RMS tumors are typically referred to as muscle cancers because they resemble histologically aberrant muscle differentiation states and often originate in or near muscle beds. Yet, these tumors arise virtually anywhere in the body, including anatomic sites that lack skeletal muscle, such as the biliary and genitourinary tract (Dagher and Helman 1999). Also, cells of both myogenic and nonmyogenic lineage have been shown to contribute to the development of specific RMS-like tumors in mice (Rubin et al. 2011; Hatley et al. 2012). To a great extent, it is unknown to what degree the tissue environment at the primary site, the differentiation state of the cells in which tumorigenic events occur, the specific oncogenic events acquired during transformation, or combinations of these factors determine tumor phenotypes across the RMS spectrum (Hettmer and Wagers 2010).

Differing clinicopathologic RMS phenotypes were recognized first based on their histological appearance and, more recently, based on the genetic makeup of tumors (Parham 2001). The two main histological subtypes diagnosed in the pediatric population are alveolar and embryonal RMS, whereas tumors with pleomorphic and not otherwise specified (NOS) histology account for the majority of RMS diagnosed in individuals $>18$ years of age (Parham 2001; Sultan et al. 2009; Hawkins et al. 2013). Chromosomal translocations resulting in fusion of the DNA-binding domain of the $P A X 3$ or $P A X 7$ genes to the transactivation domain of the FOXO1 gene (previously known as FKHR) have been detected in approximately 55\% (PAX3-FOXO1) and 20\% (PAX7-FOXO1) of alveolar histology RMS (Sorensen et al. 2002). Conversely, a small subset of tumors with alveolar histology is fusion-negative $(\sim 20 \%)$, and nonalveolar (mostly embryonal) RMS tumors never carry PAX-FOXO1 fusions (Sorensen et al. 2002). Fusion-negative alveolar tumors are clinically and molecularly indistinguishable from the larger group of fusion-negative nonalveolar tumors (Williamson et al. 2010). In contrast, there are marked differences in the genetic makeup of fusion-positive and fusionnegative tumors; for example, fusion-positive RMS tumors have frequent amplification events,

\section{BOX 1. THE BANBURY CENTER AT COLD SPRING HARBOR LABORATORY}

The Banbury Center was established in 1977 as a venue for "think-tank" meetings on important topics in molecular biology, genetics, neuroscience, cancer research, and science policy. The center has now hosted more than 600 Banbury Meetings and more than 12,000 participants. Each meeting convenes 20-30 of the leading figures in a field to present and discuss unpublished work, with the aim of identify-

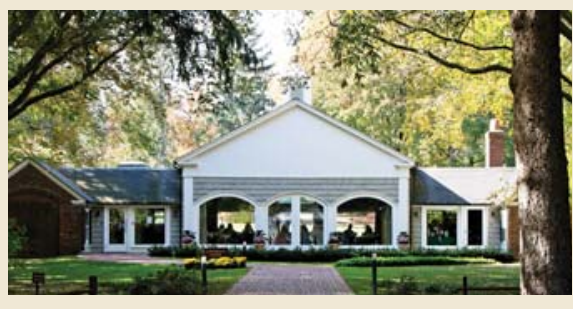
ing the key questions and challenges facing researchers. The Banbury White Papers published in CSH Perspectives were devised as a framework for distilling these conclusions and disseminating them to the wider research community. 
distinct DNA methylation patterns, and extremely low sequence variation rates, as opposed to loss of heterozygosity at the $11 \mathrm{p} 15.5$ locus, frequent chromosomal gains, and a prominent role for RAS pathway activation in fusion-negative tumors (Xia et al. 2002; Langenau et al. 2007; Hettmer et al. 2011; Chen et al. 2013; Schneider et al. 2014; Shern et al. 2014).

Approximately $46 \%$ of fusion-positive RMS and $17 \%$ of fusion-negative RMS diagnosed in the pediatric age group have formed radiographically detectable metastases at the time of diagnosis, most frequently localizing to the lungs (Williamson et al. 2010; Hawkins et al. 2013). However, even those without detectable metastases almost always carry microscopic seeds of tumor cells in regional lymph nodes and/or distant organs. Effective anti-RMS treatments therefore need to provide control of both the primary tumor (local control) and of distant tumor cell seeds (systemic therapy).

Since the 1970s, collaborative pediatric trials have developed and established multimodal anti-RMS therapeutic strategies, including surgery, radiation, and combinations of conventional chemotherapeutic drugs (Pappo et al. 1995). These therapies have revolutionized pediatric RMS care and achieved $61 \%$ overall survival of children and adolescents diagnosed with RMS (Sultan et al. 2009) compared with 25\%$30 \%$ survival in the 1960 s using primarily local therapy (i.e., surgery and radiation) (Pappo et al. 1995). Yet, unfortunately, cure rates have stagnated since the 1990s and distribute unequally across the varied spectrum of this cancer. Of those children diagnosed with PAX-FOXO1positive (including metastatic and nonmetastatic tumors [Williamson et al. 2010; Missiaglia et al. 2012]) or overtly metastatic RMS (including fusion-positive and fusion-negative tumors [Oberlin et al. 2008]), $>70 \%$ die from their cancer even with the most advanced multimodal therapies. Similarly, $>70 \%$ of adults diagnosed with RMS succumb to their disease (Sultan et al. 2009). Those who do survive childhood RMS face a lifetime of significant treatment-related effects including profound functional and cosmetic deficits, organ toxicities, and second cancers (Punyko et al. 2005).
Hope for future anti-RMS therapies may rest in large part on interventions that recruit antitumor immune mechanisms, induce myogenic differentiation, or interfere with specific cellular and molecular mechanisms that drive the malignant behavior of RMS cells (Ciarapica et al. 2013; Highfill et al. 2014; Walters et al. 2014). Unfortunately, the preclinical anti-RMS activity of targeted agents such as mTOR inhibitors (Hosoi et al. 1999) and neutralizing IGF1 receptor antibodies (Mayeenuddin et al. 2010) have not translated thus far into durable objective response rates in early-phase clinical trials (Geoerger et al. 2012; Pappo et al. 2014; Weigel et al. 2014). However, improved event-free survival of individuals with relapsed RMS after treatment with the mTOR inhibitor temsirolimus in combination with vinorelbine and cyclophosphamide supports experimental strategies involving combinations of targeted agents and established drugs (Mascarenhas et al. 2014). In May 2014, a group of skeletal muscle and sarcoma biologists, clinicians, and patient advocates met for 3 days at the Banbury Center at Cold Spring Harbor, NY (Box 1) to discuss current challenges in RMS research and opportunities for developing therapies with the long-term goal of making RMS a uniformly survivable disease. This white paper outlines the clinical and biological problems (identified by this group) as those that should drive future research initiatives (see Fig. 1).

\section{CRITICAL CLINICAL PROBLEMS}

1. Failure to provide adequate local control is an important cause of treatment failure in RMS (Wharam et al. 2004), and current local control interventions contribute substantially to long-term functional deficits and second cancers in those who achieve durable remissions (Punyko et al. 2005).

2. Most RMS tumors are systemic cancers with both early regional cancer growth and distant spread of cancer cells. Metastatic disease is a major contributor to death in primary and relapsed RMS (Pappo et al. 1995; Oberlin et al. 2008). 
S. Hettmer et al.

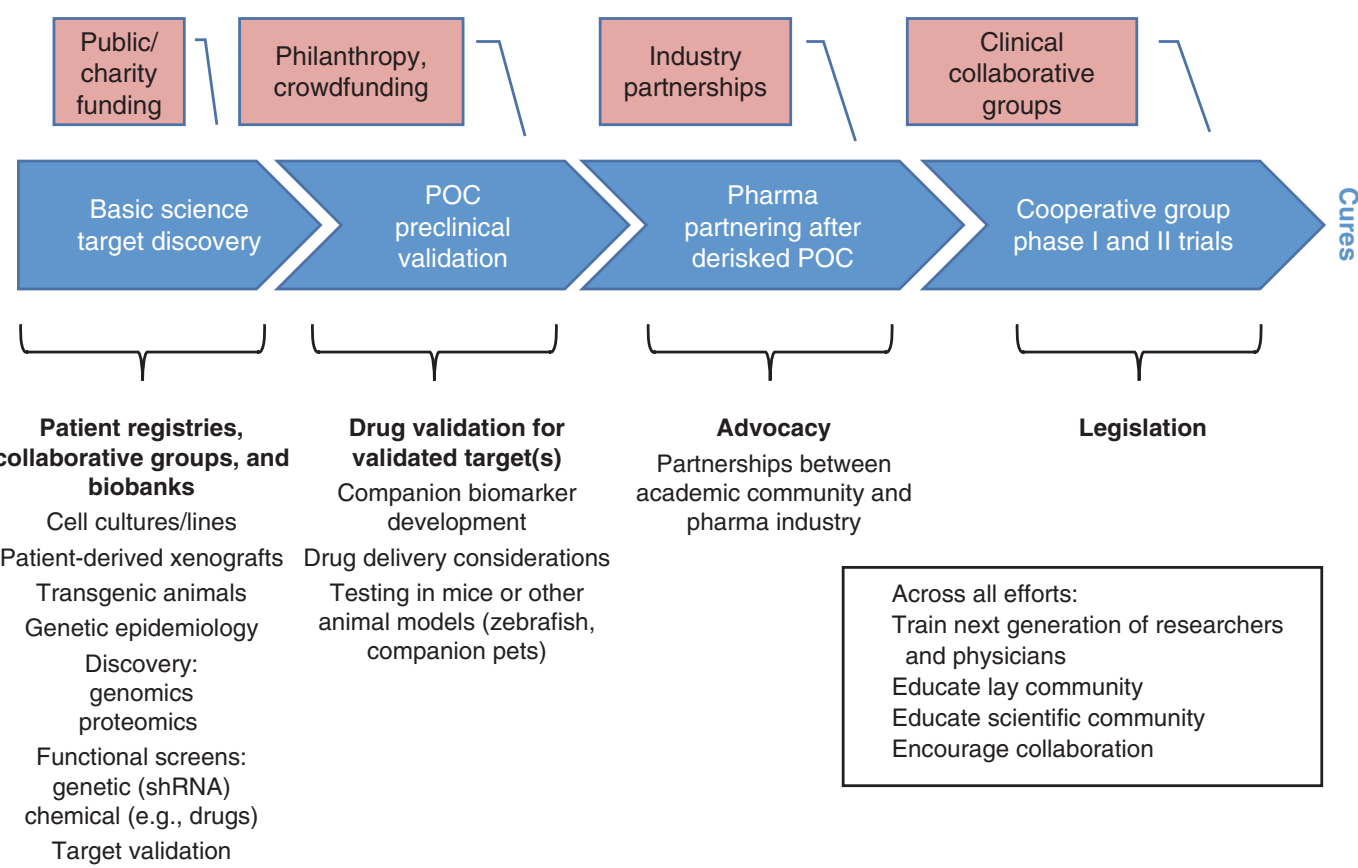

Figure 1. Rhabdomyosarcoma roadmap. Developing curative anti-RMS treatments will depend on collaborative efforts between academia, the pharmaceutical and biotechnology industries, and clinical collaborative groups (for example, the Children's Oncology Group [COG] and European Collaborative Groups), with support from public, charity, philanthropy, and crowd funding. The Sarcoma Alliance for Research through Collaboration and collaborative efforts between large sarcoma centers may allow access to adult RMS cases. Basic science discovery work will identify candidate targets and therapeutic agents for preclinical validation and proof of concept (POC) studies. Early collaborations with industry will be critical. The highest-priority targets/agents will be further developed, and early-phase clinical trials will be performed via existing collaborative group mechanisms. Across all these efforts, training of the next generation of physicians and researchers, education, and collaboration will be of critical importance.

3. Risk of treatment failure in pediatric RMS is stratified based on primary site, histology, and extent of disease. These stratification parameters do not currently include genotypic differences between fusion-positive and fusion-negative RMS or the full range of clinical, histological, and molecular variability seen across the RMS spectrum (Parham 2001; Xia et al. 2002; Missiaglia et al. 2012; Skapek et al. 2013).

4. $40 \%$ of all RMS tumors are diagnosed in adults, including individuals in the adolescent and young adult group (18-40 years of age) and older adults ( $>40$ years of age) (Sultan et al. 2009; Egas-Bejar and Huh 2014). Adult RMS attracts very little atten- tion, but overall survival in this age group is only $27 \%$ (Sultan et al. 2009). The clinical behavior, pathobiological identity, and therapeutic requirements of RMS in adults are largely unknown.

5. Several well-characterized, cancer-predisposing syndromes, including but not limited to Li Fraumeni, Neurofibromatosis type 1, and Costello syndrome (linked to germline mutations in TP53, NF1I, and HRAS), confer susceptibility to develop RMS (Kratz et al. 2011; Hettmer et al. 2014). However, the actual prevalence of cancer-predisposing germline mutations in people diagnosed with RMS and the therapeutic requirements of syndromic RMS are not known. 


\section{CRITICAL BIOLOGICAL PROBLEMS}

1. PAX-FOXO1-positive RMS shows a higher propensity to metastasize and reduced survival after currently available multimodal treatment when compared with fusion-negative tumors (Williamson et al. 2010). Understanding of the mechanisms by which the fusion product impacts malignancy and how to interfere with these mechanisms or the fusion products themselves remains insufficient.

2. RMS tumors show variable skeletal muscle differentiation markers, and some tumors show a propensity to enter terminal myogenic differentiation after chemotherapy. Yet, chemotherapy-induced cytodifferentiation in RMS, more commonly observed in fusion-negative than in $P A X-F O X O 1$-positive tumors, is generally incomplete (Coffin et al. 1997; Smith et al. 2002). A better understanding of the mechanisms that drive terminal myodifferentiation in RMS cells is needed.

3. Pathobiological heterogeneity across the RMS spectrum is poorly annotated, particularly with regard to the phenotypic differences between PAX3-FOXO1- and PAX7-FOXO1-fusion-positive RMS (Skapek et al. 2013), and the marked clinical, morphological, and genetic variability across the fusion-negative spectrum (Parham 2001; Xia et al. 2002).

4. The use of combinations of conventional cytostatic drugs revolutionized pediatric RMS treatment in the 1970s (Pratt et al. 1972). It is likely that the use of combinations of targeted agents will be critical to success in future anti-RMS therapeutic developments. Thus, rational approaches to prioritize and select drug combinations, for example by high-throughput screening or computational modeling, are needed.

5. RMS tumors originating at different body sites show markedly discrepant clinical behavior, and primary tumor site has long been recognized as a risk factor in RMS. For example, cure rates are substantially higher for RMS tumors arising in periorbital muscles compared with those originating in extremity muscles (Dagher and Helman 1999). Yet, very little is known with respect to contributions of the local microenvironment and cell of origin to RMS phenotype and behavior.

6. Phenotypically and functionally distinct subsets of cells with differential ability to repopulate tumors in secondary recipients, to selfrenew, and to migrate were identified in models of fusion-negative RMS (Walter et al. 2011; Ignatius et al. 2012). However, potential differences in drug sensitivities between individual RMS cell subsets and their clonal evolution over time are not known. Moreover, the phenotype and differential tumor-repopulating/metastasis-initiating activity of cell subsets within the $P A X-F O X O 1$ positive tumor cell pool remain poorly understood. Molecular characterization of specific, functionally relevant cell populations will likely open new therapeutic windows.

\section{STRATEGIC CONSIDERATIONS}

1. RMS is a rare cancer. Families affected by this cancer, patient advocates, clinicians, and scientists need to coalesce their efforts to garner sufficient support from funding sources and the pharmaceutical industry to support the development of curative therapies. Existing preliminary data, strategic considerations by relevant pediatric collaborative groups, and a deep clinical need may provide a fertile ground for partnerships between academic groups and industry (Sokolowski et al. 2014).

2. Insufficient access to fresh RMS tissue has hindered progress in RMS research. Moreover, there are few existing human RMS cell lines, and these lines are not widely distributed (Sokolowski et al. 2014). Tumor biology initiatives are needed to collect sufficient amounts of fresh tumor material from patients with RMS (both children and adults) to support tumor profiling efforts and the generation, long-term storage, and distribution of new cell lines and xenografts for experimentation. 
S. Hettmer et al.

3. Recent efforts to move new candidate drugs with anti-RMS activity into the clinic are primarily built on early-phase clinical trials designed to test single agents in heavily pretreated patients with bulky disease. Alternative trial designs should be considered to allow for (1) testing of rationally selected combinations of drugs, (2) evaluation of drug effects in a minimal residual disease setting (such as maintenance therapy), and (3) mandatory tumor biopsies before enrollment to facilitate identification of response markers.

4. New model systems and new perspectives, especially from the skeletal muscle biology community, may have substantial positive impact on RMS research.

\section{PARTNERSHIPS BETWEEN ACADEMIA AND INDUSTRY}

Access to primary human RMS tissue traditionally has been limited to academic medical institutions. However, the current funding environment significantly restrains academia's capacity to support deep genetic characterization and pharmacological interrogation of primary human RMS tissue and representative cell lines with the goal of identifying key regulatory pathways that may ultimately yield drug targets. Regrettably, the scarcity of samples also has dissuaded large pharmaceutical and biotechnology companies, the very entities with the capacity for large-scale genomic studies and screening, from investing in this area of drug discovery. To accelerate RMS research in the current funding environment, it is critical to establish sustainable collaborative partnerships between clinical centers, academic research groups, and industry to allow pharmaceutical and biotechnology companies to contribute their unique resources to generate comprehensive RMS data sets. The resulting data should be publically available and published in a timely manner. Such collaborative efforts will provide academic researchers with high-quality data allowing fundamental insights into RMS malignancy, and industry partners will be able to leverage this data to develop drug sensitivity testing and, perhaps, identify new drugs and new uses for previously established medicines.

One successful example for a productive partnership between academia and industry is the Cancer Cell Line Encyclopedia (CCLE) project, a collaborative project between Novartis and the Broad Institute. The CCLE provides a comprehensive set of data on 1000 cancer cell lines that has proven to be useful for cancer characterization and target identification (Barretina et al. 2012). Importantly, this resource was made public, even though Novartis assumed a significant portion of the cost. New cell lines, primary tissues, and primary tumor xenografts are currently being added, including samples representing rare tumor entities. Tumor prevalence is not a major criterion for inclusion, but a robust logistic framework allowing access to tumor material is needed.

The acquisition and transfer of primary tumor material between academic medical centers and industry partners could be facilitated by mutually agreed on standards between academic institutions and companies concerning patient consent forms, material transfer agreements (MTAs), and collection/distribution fees. Umbrella agreements between clinical groups and industry partners could circumvent the need to obtain individual MTAs for new samples, and thereby accelerate progress. An oversight committee representing all interested parties should supervise the collaborative effort to prioritize common interests and secure transparency.

\section{ACKNOWLEDGMENTS}

The authors are grateful to the Michelle Paternoster Foundation for Sarcoma Research, the Christina Renna Foundation Inc., and the Friends of T.J. Foundation for lending their voice and financial support, and to the staff at the Banbury Center at Cold Spring Harbor Laboratory, NY for their interest and for hosting the RMS meeting in May 2014.

\section{CONTRIBUTOR AFFILIATIONS}

Simone Hettmer, Charité, University Hospital Berlin, Pediatric Hematology/Oncology, 10439 Berlin, Germany 
Zhizhong Li, Genomics Institute of the Novartis Research Foundation; Novartis Institutes for Biomedical Research, San Diego, California 92121

Andrew N. Billin, GlaxoSmithKline, Research Triangle Park, Durham, North Carolina 27709

Frederic G. Barr, National Cancer Institute, Bethesda, Maryland 20892

D. D. W. Cornelison, University of Missouri, Columbia, Missouri 65211

Alan R. Ehrlich, Focus on Rhabdo, New York, New York

Denis C. Guttridge, Ohio State University, Columbus Ohio 43210

Andrea Hayes-Jordan, University of Texas Medical School, Houston, Texas 77030

Lee J. Helman, National Cancer Institute, Bethesda, Maryland 20892

Peter J. Houghton, Nationwide Children's Research Institute, Columbus, Ohio 43205

Javed Khan, National Cancer Institute, Bethesda, Maryland 20892

David M. Langenau, Massachusetts General Hospital, Charlestown, Massachusetts 02129

Corinne M. Linardic, Duke University School of Medicine, Durham, North Carolina 27710

Ranadip Pal, Department of Electrical and Computer Engineering, Texas Tech University, Lubbock, Texas 79409

Terence A. Partridge, Children's National Medical Center, Washington, DC 20010

Grace K. Pavlath, Emory University School of Medicine, Atlanta Georgia 30322

Rossella Rota, Department of Oncohematology, Ospedale Pediatrico Bambino Gesù, 00165 Roma, Italy

Beat W. Schäfer, University Children's Hospital, 8032 Zurich, Switzerland

Janet Shipley, The Institute of Cancer Research, Sutton, Surrey SM2 5NG, United Kingdom

Bruce Stillman, Cold Spring Harbor Laboratory, Cold Spring Harbor, New York 11724

Leonard H. Wexler, Memorial Sloan-Kettering Cancer Center, New York, New York 10065

Amy J. Wagers, Howard Hughes Medical Institute, Department of Stem Cell and Regenerative Biology, Harvard University, Harvard Stem Cell Institute, and Joslin Diabetes Center, Cambridge, Massachusetts 02138

Charles Keller, Pediatric Cancer Biology Program, Papé Family Pediatric Research Institute, Department of Pediatrics, Oregon Health \& Science University, Portland, Oregon 97239; Children's Cancer Therapy Development Institute, Fort Collins, Colorado 80524

\section{REFERENCES}

Barretina J, Caponigro G, Stransky N, Venkatesan K, Margolin AA, Kim S, Wilson CJ, Lehar J, Kryukov GV, Sonkin D, et al. 2012. The Cancer Cell Line Encyclopedia enables predictive modelling of anticancer drug sensitivity. $\mathrm{Na}$ ture 483: 603-607.

Chen EY, Dobrinski KP, Brown KH, Clagg R, Edelman E, Ignatius MS, Chen JY, Brockmann J, Nielsen GP, Ramaswamy S, et al. 2013. Cross-species array comparative genomic hybridization identifies novel oncogenic events in zebrafish and human embryonal rhabdomyosarcoma. PLoS Genet 9: e1003727.

Ciarapica R, De Salvo M, Carcarino E, Bracaglia G, Adesso L, Leoncini PP, Dall'agnese A, Walters ZS, Verginelli F, De Sio L, et al. 2013. The Polycomb group (PcG) protein EZH2 supports the survival of PAX3-FOXO1 alveolar rhabdomyosarcoma by repressing FBXO32 (Atrogin1/ MAFbx). Oncogene 33: 4173-4184.

Coffin CM, Rulon J, Smith L, Bruggers C, White FV. 1997. Pathologic features of rhabdomyosarcoma before and after treatment: A clinicopathologic and immunohistochemical analysis. Mod Pathol 10: 1175-1187.

Dagher R, Helman L. 1999. Rhabdomyosarcoma: An overview. Oncologist 4: 34-44.

Egas-Bejar D, Huh WD. 2014. Rhabdomyosarcoma in adolescent and young adult patients: Current perspectives. Adolesc Health Med Ther 5: 115-125.

Geoerger B, Kieran MW, Grupp S, Perek D, Clancy J, Krygowski M, Ananthakrishnan R, Boni JP, Berkenblit A, Spunt SL. 2012. Phase II trial of temsirolimus in children with high-grade glioma, neuroblastoma and rhabdomyosarcoma. Eur J Cancer 48: 253-262.

Hatley ME, Tang W, Garcia MR, Finkelstein D, Millay DP, Liu N, Graff J, Galindo RL, Olson EN. 2012. A mouse model of rhabdomyosarcoma originating from the adipocyte lineage. Cancer Cell 22: 536-546.

Hawkins DS, Spunt SL, Skapek SX. 2013. Children's Oncology Group's 2013 blueprint for research: Soft tissue sarcomas. Pediatr Blood Cancer 60: 1001-1008.

Hettmer S, Wagers AJ. 2010. Muscling in: Uncovering the origins of rhabdomyosarcoma. Nat Med 16: 171-173.

Hettmer S, Liu J, Miller CM, Lindsay MC, Sparks CA, Guertin DA, Bronson RT, Langenau DM, Wagers AJ. 2011. Sarcomas induced in discrete subsets of prospectively isolated skeletal muscle cells. Proc Natl Acad Sci 108: 20002-20007.

Hettmer S, Archer NM, Somers GR, Novokmet A, Wagers AJ, Diller L, Rodriguez-Galindo C, Teot LA, Malkin D. 2014. Anaplastic rhabdomyosarcoma in TP53 germline mutation carriers. Cancer 120: 1068-1075.

Highfill SL, Cui Y, Giles AJ, Smith JP, Zhang H, Morse E, Kaplan RN, Mackall CL. 2014. Disruption of CXCR2mediated MDSC tumor trafficking enhances anti-PD1 efficacy. Sci Transl Med 6: 237ra67.

Hosoi H, Dilling MB, Shikata T, Liu LN, Shu L, Ashmun RA, Germain GS, Abraham RT, Houghton PJ. 1999. Rapamycin causes poorly reversible inhibition of mTOR and induces p53-independent apoptosis in human rhabdomyosarcoma cells. Cancer Res 59: 886-894.

Ignatius MS, Chen E, Elpek NM, Fuller AZ, Tenente IM, Clagg R, Liu S, Blackburn JS, Linardic CM, Rosenberg $\mathrm{AE}$, et al. 2012. In vivo imaging of tumor-propagating cells, regional tumor heterogeneity, and dynamic cell movements in embryonal rhabdomyosarcoma. Cancer Cell 21: 680-693.

Kratz CP, Rapisuwon S, Reed H, Hasle H, Rosenberg PS. 2011. Cancer in Noonan, Costello, cardiofaciocutaneous and LEOPARD syndromes. Am J Med Genet C Semin Med Genet 157C: 83-89. 
S. Hettmer et al.

Langenau DM, Keefe MD, Storer NY, Guyon JR, Kutok JL, Le X, Goessling W, Neuberg DS, Kunkel LM, Zon LI. 2007. Effects of RAS on the genesis of embryonal rhabdomyosarcoma. Genes Dev 21: 1382-1395.

Mascarenhas L, Meyer BH, Lyden E, Rodeberg DA, Indelicato DJ, Linardic CM, Anderson JR, Hawkins DS 2014. Randomized phase II trial of bevacizumab and temsirolimus in combination with vinorelbine $(\mathrm{V})$ and cyclophosphamide (C) for first relapse/disease progression of rhabdomyosarcoma (RMS): A report from the Children's Oncology Group (COG). J Clin Oncol 32 (Suppl): 5s.

Mayeenuddin LH, Yu Y, Kang Z, Helman LJ, Cao L. 2010. Insulin-like growth factor 1 receptor antibody induces rhabdomyosarcoma cell death via a process involving AKT and $\mathrm{Bcl}-\mathrm{x}(\mathrm{L})$. Oncogene 29: 6367-6377.

Missiaglia E, Williamson D, Chisholm J, Wirapati P, Pierron G, Petel F, Concordet JP, Thway K, Oberlin O, PritchardJones K, et al. 2012. PAX3/FOXO1 fusion gene status is the key prognostic molecular marker in rhabdomyosarcoma and significantly improves current risk stratification. J Clin Oncol 30: 1670-1677.

Oberlin O, Rey A, Lyden E, Bisogno G, Stevens MC, Meyer WH, Carli M, Anderson JR. 2008. Prognostic factors in metastatic rhabdomyosarcomas: Results of a pooled analysis from United States and European cooperative groups. J Clin Oncol 26: 2384-2389.

Pappo AS, Shapiro DN, Crist WM, Maurer HM. 1995. Biology and therapy of pediatric rhabdomyosarcoma. J Clin Oncol 13: 2123-2139.

Pappo AS, Vassal G, Crowley JJ, Bolejack V, Hogendoorn PC, Chugh R, Ladanyi M, Grippo JF, Dall G, Staddon AP, et al. 2014. A phase 2 trial of R1507, a monoclonal antibody to the insulin-like growth factor-1 receptor (IGF-1R), in patients with recurrent or refractory rhabdomyosarcoma, osteosarcoma, synovial sarcoma, and other soft tissue sarcomas: Results of a Sarcoma Alliance for Research Through Collaboration study. Cancer 120: 2448-2456.

Parham DM. 2001. Pathologic classification of rhabdomyosarcomas and correlations with molecular studies. Mod Pathol 14: 506-514.

Perez EA, Kassira N, Cheung MC, Koniaris LG, Neville HL, Sola JE. 2011. Rhabdomyosarcoma in children: A SEER population based study. J Surg Res 170: e243-e251.

Pratt CB, Hustu HO, Fleming ID, Pinkel D. 1972. Coordinated treatment of childhood rhabdomyosarcoma with surgery, radiotherapy, and combination chemotherapy. Cancer Res 32: 606-610.

Punyko JA, Mertens AC, Gurney JG, Yasui Y, Donaldson SS, Rodeberg DA, Raney RB, Stovall M, Sklar CA, Robison LL, et al. 2005. Long-term medical effects of childhood and adolescent rhabdomyosarcoma: A report from the childhood cancer survivor study. Pediatr Blood Cancer 44: 643-653.

Rubin BP, Nishijo K, Chen HI, Yi X, Schuetze DP, Pal R, Prajapati SI, Abraham J, Arenkiel BR, Chen QR, et al. 2011. Evidence for an unanticipated relationship between undifferentiated pleomorphic sarcoma and embryonal rhabdomyosarcoma. Cancer Cell 19: 177-191.

Schneider G, Bowser MJ, Shin DM, Barr FG, Ratajczak MZ. 2014. The paternally imprinted DLK1-GTL2 locus is differentially methylated in embryonal and alveolar rhabdomyosarcomas. Int J Oncol 44: 295-300.
Shern JF, Chen L, Chmielecki J, Wei JS, Patidar R, Rosenberg M, Ambrogio L, Auclair D, Wang J, Song YK, et al. 2014. Comprehensive genomic analysis of rhabdomyosarcoma reveals a landscape of alterations affecting a common genetic axis in fusion-positive and fusion-negative tumors. Cancer Discov 4: 216-231.

Skapek SX, Anderson J, Barr FG, Bridge JA, Gastier-Foster JM, Parham DM, Rudzinski ER, Triche T, Hawkins DS. 2013. PAX-FOXO1 fusion status drives unfavorable outcome for children with rhabdomyosarcoma: A children's oncology group report. Pediatr Blood Cancer 60: 1411-1417.

Smith LM, Anderson JR, Coffin CM. 2002. Cytodifferentiation and clinical outcome after chemotherapy and radiation therapy for rhabdomyosarcoma (RMS). Med Pediatr Oncol 38: 398-404.

Sokolowski E, Turina CB, Kikuchi K, Langenau DM, Keller C. 2014. Proof-of-concept rare cancers in drug development: The case for rhabdomyosarcoma. Oncogene 33: 1877-1889.

Sorensen PH, Lynch JC, Qualman SJ, Tirabosco R, Lim JF, Maurer HM, Bridge JA, Crist WM, Triche TJ, Barr FG. 2002. PAX3-FKHR and PAX7-FKHR gene fusions are prognostic indicators in alveolar rhabdomyosarcoma: A report from the children's oncology group. J Clin Oncol 20: $2672-2679$.

Sultan I, Qaddoumi I, Yaser S, Rodriguez-Galindo C, Ferrari A. 2009. Comparing adult and pediatric rhabdomyosarcoma in the surveillance, epidemiology and end results program, 1973 to 2005: An analysis of 2,600 patients. $J$ Clin Oncol 27: 3391-3397.

Walter D, Satheesha S, Albrecht P, Bornhauser BC, D'Alessandro V, Oesch SM, Rehrauer H, Leuschner I, Koscielniak E, Gengler C, et al. 2011. CD133 positive embryonal rhabdomyosarcoma stem-like cell population is enriched in rhabdospheres. PLoS ONE 6: e19506.

Walters ZS, Villarejo-Balcells B, Olmos D, Buist TW, Missiaglia E, Allen R, Al-Lazikani B, Garrett MD, Blagg J, Shipley J. 2014. JARID2 is a direct target of the PAX3-FOXO1 fusion protein and inhibits myogenic differentiation of rhabdomyosarcoma cells. Oncogene 33: 1148-1157.

Weigel B, Malempati S, Reid JM, Voss SD, Cho SY, Chen HX, Krailo M, Villaluna D, Adamson PC, Blaney SM. 2014. Phase 2 trial of cixutumumab in children, adolescents, and young adults with refractory solid tumors: a report from the Children's Oncology Group. Pediatr Blood Cancer 61: 452-456.

Wharam MD, Meza J, Anderson J, Breneman JC, Donaldson SS, Fitzgerald TJ, Michalski J, Teot LA, Wiener ES, Meyer WH. 2004. Failure pattern and factors predictive of local failure in rhabdomyosarcoma: A report of group III patients on the third Intergroup Rhabdomyosarcoma Study. J Clin Oncol 22: 1902-1908.

Williamson D, Missiaglia E, de Reynies A, Pierron G, Thuille B, Palenzuela G, Thway K, Orbach D, Lae M, Freneaux P, et al. 2010. Fusion gene-negative alveolar rhabdomyosarcoma is clinically and molecularly indistinguishable from embryonal rhabdomyosarcoma. J Clin Oncol 28: 21512158.

Xia SJ, Pressey JG, Barr FG. 2002. Molecular pathogenesis of rhabdomyosarcoma. Cancer Biol Ther 1: 97-104. 


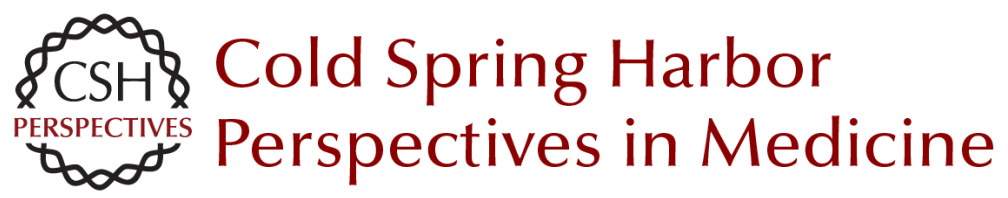

\section{Rhabdomyosarcoma: Current Challenges and Their Implications for Developing Therapies}

Simone Hettmer, Zhizhong Li, Andrew N. Billin, Frederic G. Barr, D.D.W. Cornelison, Alan R. Ehrlich, Denis C. Guttridge, Andrea Hayes-Jordan, Lee J. Helman, Peter J. Houghton, Javed Khan, David M. Langenau, Corinne M. Linardic, Ranadip Pal, Terence A. Partridge, Grace K. Pavlath, Rossella Rota, Beat W. Schäfer, Janet Shipley, Bruce Stillman, Leonard H. Wexler, Amy J. Wagers and Charles Keller

Cold Spring Harb Perspect Med 2014; doi: 10.1101/cshperspect.a025650

Subject Collection

For additional articles in this collection, see http://perspectivesinmedicine.cshlp.org/cgi/collection/ 